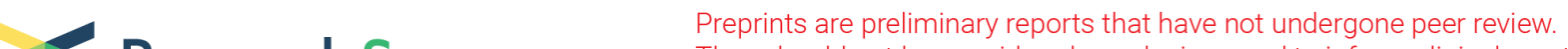 $\begin{array}{ll}\text { Research Square } & \begin{array}{l}\text { They should not be considered conclusive, used to inform clinical practice, } \\ \text { or referenced by the media as validated information. }\end{array}\end{array}$
}

\section{Validation and modification of existing mortality prediction model for lower gastrointestinal bleeding: A retrospective study}

Hyun Suk Lee

Chungnam National University Hospital

Hee Seok Moon ( $\sim$ mhs1357@cnuh.co.kr)

Chungnam National University School of Medicine https://orcid.org/0000-0002-8806-2163

In Sun Kwon

Chungnam National University

Hyun Yong Jeong

Chungnam National University Hospital

Byung Seok Lee

Chungnam National University Hospital

Seok Hyun Kim

Chungnam National University Hospital

\section{Eaum-Seok Lee}

Chungnam National University Hospital

Jae Kyu Sung

Chungnam National University Hospital

\section{Sun Hyung Kang}

Chungnam National University Hospital

\section{Research article}

Keywords: Lower gastrointestinal bleeding, , hematochezia, scoring system, mortality prediction

Posted Date: July 13th, 2021

DOl: https://doi.org/10.21203/rs.3.rs-701789/v1

License: (c) (i) This work is licensed under a Creative Commons Attribution 4.0 International License. Read Full License

Version of Record: A version of this preprint was published at BMC Gastroenterology on November 29th, 2021. See the published version at https://doi.org/10.1186/s12876-021-02037-4. 


\section{Abstract \\ Background}

Lower gastrointestinal bleeding (LGIB) often subsides by itself; however, in some cases, the bleeding does not stop and the patient's condition worsens. Therefore, if the occurrence of severe lower gastrointestinal bleeding can be predicted in advance, it can be helpful for treatment. This study aimed to evaluate variables related to mortality from LGIB and to propose a scoring system.

\section{Methods}

This retrospective study reviewed the medical records of patients who visited the emergency room with hematochezia between January 2016 and December 2020. Through regression analysis of vital signs, laboratory investigations, and hospital stay, variables related to LGIB-related mortality were evaluated. A scoring system was developed, and the appropriateness with an area under the receiver operating characteristics curve (AUROC) was evaluated and compared with other existing models.

\section{Results}

A total of 932 patients were hospitalized for LGIB. Variables associated with LGIB-related mortality were the presence of cancer, heart rate of $>100$ beats $/ \mathrm{min}$, blood urea nitrogen level of $\geq 30 \mathrm{mg} / \mathrm{dL}$, an international normalized ratio of $>1.50$, and albumin level of $\leq 3.0 \mathrm{~g} / \mathrm{dL}$. The AUROCs of CNUH-4 and CNUH-5 were 0.890 ( $p<0.001$; cutoff, $2.5 ; 95 \%$ confidence interval, $0.0851-0.929)$ and $0.901(p<0.001$; cutoff, 3.5; $95 \%$ confidence interval, $0.869-0.933)$, respectively.

\section{Conclusions}

The model developed for predicting the risk of LGIB-related mortality is simple and easy to apply clinically. The AUROC of the model was better than that of the existing models.

\section{Background}

Gastrointestinal bleeding (GIB) is anatomically divided based on the ligament of Treitz. Upper gastrointestinal bleeding (UGIB) is defined as bleeding above the ligament of Treitz, while lower gastrointestinal bleeding (LGIB) is defined as bleeding below the ligament of Treitz. Recently, with the introduction of small intestine endoscopy, small intestine bleeding is referred to as mid-gut bleeding, while colon and rectal bleeding below the ileocecal valve is called LGIB [1]. LGIB accounts for $20-40 \%$ of all GIB [1] [2] [3]. Compared with past data, the incidence of UGIB has reduced, whereas that of LGIB has increased. In the United States, the incidence of UGIB was 87 per 100,000 individuals in 1996 but 
decreased to 47 per 100,000 individuals in 2005. By contrast, the incidence of LGIB was 20 per 100,000 individuals in 1996 but increased to 33 per 100,000 individuals in 2005 [4] [5].

Various studies have evaluated the risk factors and mortality related to UGIB. Evaluation methods, such as AIMS65 [6] and Protetto Nazionale Emorragia Digestiva [7], which can predict UGIB-related mortality, and the Glasgow Blatchford Score (GBS) [8], which predict the need for intervention after hospitalization, have been developed and applied in clinical practice. However, studies on LGIB are fewer than those on UGIB. This is because the incidence of LGIB is less than that of UGIB, and $80-85 \%$ of LGIB cases improve spontaneously without requiring hospitalization [9]. However, various studies are currently being undertaken to evaluate the mortality, severity, and risk factors of LGIB.

Compared with UGIB, no specific method has been established for evaluating the severity of LGIB; hence, AIMS65, which is used for UGIB evaluation, is also being used for LGIB evaluation. Recently, the ABC score has been successfully developed for predicting LGIB-related mortality [10]. Thus, in this study, we aimed to evaluate variables related to mortality from LGIB and to propose a scoring system.

\section{Methods}

\section{Study design and population}

In this retrospective study, all patient information was obtained through electronic medical records. Patients with hematochezia aged $>19$ years who visited the emergency room (ER) of Chungnam National University Hospital from 1 January 2016 to 31 December 2020 were included. Among them, patients who were discharged from the hospital on the same day after treatment in the ER were excluded, and only patients who received inpatient treatment were included. Causes of LGIB were classified based on investigational results, such as duodenoscopy, colonoscopy, angiography, and abdominal hemorrhagic computed tomography (CT) among hospitalized patients.

\section{Selection of predictor candidates}

By referring to previous studies, variables that are expected to be associated with LGIB-related mortality were searched using electronic medical records. Basic patient-related information included age, sex, comorbidities (cancer, heart failure [HF], renal failure [RF], liver cirrhosis [LC], chronic obstructive pulmonary disease [COPD]), and medication history (anticoagulant, antiplatelet, non-steroidal antiinflammatory drugs [NSAIDs]). Vital signs and blood investigations (hemoglobin level, hematocrit percentage, platelet count, albumin level, blood urea nitrogen [BUN] level, creatinine level, and international normalized ratio [INR]) at the ER, hospitalization period, intensive care unit treatment period, and death were also studied.

\section{Primary outcome and definitions}

LGIB was defined as colon and rectal bleeding below the ileocecal valve, which was confirmed through duodenoscopy, colonoscopy, angiography, and hemorrhagic CT. The primary outcome was to investigate 
variables related to all-cause mortality of patients hospitalized with LGIB. The secondary outcome was to evaluate the area under the receiver operating characteristics curve (AUROC) value with the result of the primary outcome. The AUROC was compared with those of existing models (ABC and AIMS65).

\section{Statistical analyses}

Continuous variables are represented as the mean (standard deviation) or median (range) depending on the normality. Categorical variables are represented as numbers (percentages). Univariate logistic regression analysis was used to investigate variables associated with all-cause mortality. Multivariable logistic regression analysis was used to determine the actual role of each factor by correcting the influences of the variables with meaningful results. While selecting statistically meaningful variables in the univariable logistic regression analysis, to reduce the error of selecting confounding and suppressor variables, the $p$-value was set at $<0.1$. For the secondary outcome, four to five variables that were most related to all-cause mortality in the primary outcome were selected, and then each AUROC value was compared. SPSS version 22 (IBM Corp., Armonk, NY, USA) was used for the statistical analyses.

\section{Results}

\section{Patient characteristics}

From January 2016 to December 2020, 3,181 patients with hematochezia aged $\geq 19$ years older were admitted to the ER. Of them, 2,086 were discharged on the same day after treatment, and 1,095 were hospitalized for LGIB. Finally, 932 patients were diagnosed with LGIB (Fig. 1).

Among patients who underwent inpatient treatment, 627 (57.3\%) were men and 468 (42.7\%) were women. The median age was 68 years (range, 19 - 94 years). Underlying comorbidities were cancer [206 (18.8\%)], HF [131 (12.0\%)], RF [136 (12.4\%)], COPD [32 (2.9\%)], and LC [118 (10.8\%)]. The American Society of Anesthesiologists (ASA) scores were as follows: 1 point, 645 (58.9\%); 2 points, 152 (13.8\%); and 3 points, 298 (27.2\%). In the ER, 1045 patients (95.4\%) were alert, and 50 (4.5\%) had altered mental status. During hospitalization, the concomitant medications were antiplatelet agents, 206 (18.8\%); anticoagulants, 122 (11.1\%); and NSAIDs, 306 (27.9\%). The median length of hospital stay was 6 days (range, 1 - 203 days). Moreover, 51 (4.65\%) patients received intensive care treatment, and the median duration of intensive care unit treatment was 3 days (range, $1-26$ days) (Table 1). 
Table 1

Baseline characteristics of the patients.

\begin{tabular}{|c|c|c|}
\hline \multirow{3}{*}{$\begin{array}{l}\text { Parameters } \\
\text { Sex (\%) }\end{array}$} & & \\
\hline & \multicolumn{2}{|l|}{ Results } \\
\hline & Male: 627 (57.3) & Female: 468 (42.7) \\
\hline Age, median (range) & \multicolumn{2}{|l|}{$68(19-94)$} \\
\hline \multirow[t]{5}{*}{ Comorbidity (\%) } & Cancer & $206(18.8)$ \\
\hline & Heart failure & $131(12.0)$ \\
\hline & Renal failure & $136(12.4)$ \\
\hline & Chronic pulmonary obstructive disease & $32(2.9)$ \\
\hline & Liver cirrhosis & $118(10.8)$ \\
\hline \multirow[t]{3}{*}{ ASA score } & 1 & $645(58.9)$ \\
\hline & 2 & $152(13.8)$ \\
\hline & 3 & $298(27.2)$ \\
\hline \multirow[t]{2}{*}{ Mental status } & Alert & $1045(95.4)$ \\
\hline & Altered & $50(4.5)$ \\
\hline \multirow[t]{3}{*}{ Medication (\%) } & Antiplatelet & $206(18.8)$ \\
\hline & Anticoagulant & $122(11.1)$ \\
\hline & Non-steroidal anti-inflammatory drugs & $306(27.9)$ \\
\hline \multirow[t]{3}{*}{ Hospitalization } & Day, median (range) & $6.00(1-203)$ \\
\hline & Intensive care unit & $51(4.65)$ \\
\hline & day, median (range) & $3.00(1-26)$ \\
\hline \multirow[t]{3}{*}{ Mortality (\%) } & All-cause mortality & $40(3.7)$ \\
\hline & Bleeding-related mortality & $23(2.1)$ \\
\hline & Non-bleeding-related mortality & $17(1.6)$ \\
\hline \multicolumn{3}{|c|}{ ASA, American Society of Anesthesiologists } \\
\hline
\end{tabular}

The median heart rate was 100 beats/min, the median systolic blood pressure was $100 \mathrm{mmHg}$, and the median diastolic blood pressure was $53 \mathrm{mmHg}$ (Table 2). The mean hemoglobin level and hematocrit percentage were $9.24 \mathrm{~g} / \mathrm{dL}$ and $27.22 \%$, respectively. The median platelet count, BUN level, creatinine level, albumin level, and INR were 161,000/ $\mu \mathrm{L}, 22.3 \mathrm{mg} / \mathrm{dL}, 0.95 \mathrm{mg} / \mathrm{dL}, 3.0 \mathrm{~g} / \mathrm{dL}$, and 1.12, respectively 
(Table 2). Among patients who underwent inpatient treatment for LGIB, 40 (3.7\%) died; among them, 23 (2.1\%) died from LGIB and 17 (1.6\%) died from causes other than LGIB (Table 1).

Table 2

Vital signs and laboratory test results at the emergency room.

\begin{tabular}{|c|c|c|}
\hline & & \\
\hline Parameters & & Results \\
\hline \multirow[t]{3}{*}{ Vital signs (median) } & Heart rate (beat/min) & 100 \\
\hline & Systolic blood pressure (mmHg) & 100 \\
\hline & Diastolic blood pressure (mmHg) & 53 \\
\hline \multirow[t]{7}{*}{ Laboratory test results } & Hemoglobin, mean(g/dL) & 9.24 \\
\hline & Hematocrit, mean (\%) & 27.22 \\
\hline & Platelet, median $(\mu \mathrm{L})$ & 161,000 \\
\hline & Blood urea nitrogen, median $(\mathrm{mg} / \mathrm{dL})$ & 22.3 \\
\hline & Creatinine, median (mg/dL) & 0.95 \\
\hline & Albumin, median (g/dL) & 3.0 \\
\hline & International normalized ratio, median & 1.12 \\
\hline
\end{tabular}

\section{Endoscopic results}

Of 1095 patients admitted of LGIB, 850 (77.6\%) underwent endoscopy. Among them, 144 (13.2\%) patients underwent endoscopic hemostasis, 24 (2.2\%) underwent transarterial embolization, and one $(0.1 \%)$ underwent both procedures (Table 3 ). In endoscopy, the most common cause of LGIB was ischemic colitis (178 [16.3\%]), followed by diverticular bleeding (175 [16.0\%]), ulcer bleeding 75 ([6.8\%]), cancer bleeding 68 ([6.2\%]), and post-polypectomy bleeding (61 [5.6\%]). In addition, small bowel bleeding was observed in $36(3.3 \%)$ patients, ulcerative colitis in 34 (3.4\%), colitis in $30(2.7 \%)$, UGIB in 28 (2.6\%), polyp in $27(2.5 \%)$, adenoma in $13(1.2 \%)$, rectal varix bleeding in $8(0.7 \%)$, angiodysplasia in $6(0.5 \%)$, pseudomembranous colitis in $4(0.4 \%)$, arteriovenous malformation in $3(0.3 \%)$, Crohn's disease in 3 $(0.3 \%)$, subepithelial tumors in $3(0.3 \%)$, and INR prolongation in $1(0.1 \%)$. In endoscopy, $6(0.5 \%)$ patients showed bleeding; however, the cause was undetected, and 93 (8.5\%) patients had no bleeding (Table 4). 
Table 3

Proportion of patients who underwent endoscopy and intervention.

\begin{tabular}{|lll|}
\hline Intervention & & Results \\
\hline Endoscopic exam, $\mathrm{n}(\%)$ & & $850(77.6)$ \\
\hline Intervention, $\mathrm{n}(\%)$ & Endoscopic bleeding control & $144(13.2)$ \\
\cline { 2 - 3 } & Embolization & $24(2.2)$ \\
\cline { 2 - 3 } & Both of the above & $1(0.1)$ \\
\hline
\end{tabular}

Table 4

Endoscopic results.

\begin{tabular}{|ll|}
\hline Endoscopic findings & $\mathbf{n}(\%)$ \\
\hline Ischemic colitis & $178(16.3)$ \\
\hline Diverticular bleeding & $175(16.0)$ \\
\hline Ulcer bleeding & $75(6.8)$ \\
\hline Cancer bleeding & $68(6.2)$ \\
\hline Post polypectomy bleeding & $61(5.6)$ \\
\hline Ulcerative colitis & $34(3.1)$ \\
\hline Colitis & $30(2.7)$ \\
\hline Polyp & $27(2.5)$ \\
\hline Adenoma & $13(1.2)$ \\
\hline Varix bleeding & $8(0.7)$ \\
\hline Angiodysplasia & $6(0.5)$ \\
\hline Pseudomembranous colitis & $4(0.4)$ \\
\hline Arteriovenous malformation & $3(0.3)$ \\
\hline Crohn's disease & $3(0.3)$ \\
\hline Subepithelial tumor & $3(0.3)$ \\
\hline International normalized ratio prolongation & $1(0.1)$ \\
\hline
\end{tabular}

\section{Correlation with all-cause mortality}

In the univariate analysis, the following factors were associated with all-cause mortality: age $\geq 75$ years (odds ratio [OR], 2.110; $p=0.021 ; 95 \%$ confidence interval [CI], $1.120-3.977$ ), presence of cancer (OR, 2.713; $p=0.003 ; 95 \% \mathrm{Cl}, 1.403-5.246)$, heart rate $>100$ beats $/ \min (\mathrm{OR}, 9.198 ; \mathrm{p}<0.001 ; 95 \% \mathrm{Cl}, 5.333-$ 
288.086), systolic blood pressure $<100 \mathrm{mmHg}(\mathrm{OR}, 9.384 ; \mathrm{p}<0.001 ; 95 \% \mathrm{Cl}, 3.279-26.854)$, diastolic blood pressure < $60 \mathrm{mmHg}(\mathrm{OR}, 6.783 ; \mathrm{p}<0.001 ; 95 \% \mathrm{Cl}, 1.612-28.538)$; hemoglobin level of $10.0 \mathrm{mg} / \mathrm{dL}$ (OR, 2.712; $p=0.013 ; 95 \% \mathrm{Cl}, 1.238-5.945)$; hematocrit $\leq 30.0 \%$ (OR, 3.905; $p=0.07 ; 95 \% \mathrm{Cl}, 1.356-$ 7.063), platelet count $\leq 100,000 / \mu \mathrm{L}(\mathrm{OR}, 3.809 ; \mathrm{p}<0.001 ; 95 \% \mathrm{Cl}, 2.013-7.206), \mathrm{BUN} \geq 30 \mathrm{mg} / \mathrm{dL}(\mathrm{OR}$, 11.314; $p<0.001 ; 95 \% \mathrm{Cl}, 4.950-25.860)$, creatinine level of $>1.5 \mathrm{mg} / \mathrm{dL}(\mathrm{OR}, 4.429 ; \mathrm{p}<0.001 ; 95 \% \mathrm{Cl}$, $2.336-8.395)$, albumin level $\leq 3.0 \mathrm{~g} / \mathrm{dL}(\mathrm{OR}, 37.509 ; \mathrm{p}<0.001 ; 95 \% \mathrm{Cl}, 5.134-274.040)$, and INR $>1.50$ (OR, 10.321; $p<0.001 ; 95 \% \mathrm{Cl}, 5.310-20.061$ ) (Table 5). 
Table 5

Results of logistic regression analyses for risk factors of mortality from lower gastrointestinal bleeding.

\begin{tabular}{|c|c|c|c|c|c|c|}
\hline & \multicolumn{3}{|c|}{$\begin{array}{l}\text { Univariable logistic regression } \\
\text { analysis }\end{array}$} & \multicolumn{3}{|c|}{$\begin{array}{l}\text { Multivariable logistic regression } \\
\text { analysis }\end{array}$} \\
\hline & OR & $\begin{array}{l}\mathrm{p}- \\
\text { value }\end{array}$ & $95 \% \mathrm{Cl}$ & OR & $\begin{array}{l}\text { p- } \\
\text { value }\end{array}$ & $95 \% \mathrm{Cl}$ \\
\hline Aged $\geq 75$ years & 2.110 & 0.021 & $1.120-3.977$ & 1.203 & 0.641 & $0.553-2.619$ \\
\hline Male sex & 0.845 & 0.602 & $0.449-1.591$ & & & \\
\hline Cancer & 2.713 & 0.003 & $1.403-5.246$ & 2.081 & 0.071 & $0.939-4.609$ \\
\hline COPD & 0.915 & 0.931 & $0.121-6.897$ & & & \\
\hline Renal failure & 1.559 & 0.298 & $0.675-3.601$ & & & \\
\hline Heart failure & 1.373 & 0.485 & $0.564-3.339$ & & & \\
\hline Liver cirrhosis & 2.172 & 0.057 & $0.976-4.836$ & & & \\
\hline Antiplatelet & 0.758 & 0.537 & $0.314-1.830$ & & & \\
\hline Anticoagulant & 1.144 & 0.783 & $0.439-2.979$ & & & \\
\hline NSAIDs & 0.992 & 0.983 & $0.489-2.013$ & & & \\
\hline $\begin{array}{l}\text { Heart rate }(>100 \\
\text { beats } / \mathrm{min})\end{array}$ & 39.198 & 0.000 & $\begin{array}{l}5.333- \\
288.086\end{array}$ & 13.134 & 0.014 & $\begin{array}{l}1.677- \\
102.880\end{array}$ \\
\hline $\mathrm{SBP}(<100 \mathrm{mmHg})$ & 9.384 & 0.000 & $\begin{array}{l}3.279- \\
26.854\end{array}$ & 2.477 & 0.188 & $0.642-9.560$ \\
\hline DBP $(<60$ mmHg) & 6.783 & 0.009 & $\begin{array}{l}1.612- \\
28.538\end{array}$ & 0.942 & 0.950 & $0.149-5.958$ \\
\hline $\begin{array}{l}\text { Hemoglobin }(\leq 10.0 \\
\mathrm{mg} / \mathrm{dL})\end{array}$ & 2.712 & 0.013 & $1.238-5.945$ & 1.023 & 0.982 & $0.146-7.176$ \\
\hline Hematocrit ( $\leq 30.0 \%)$ & 3.905 & 0.007 & $1.356-7.063$ & 0.296 & 0.264 & $0.035-2.501$ \\
\hline Platelet $(\leq 100,000 / u L)$ & 3.809 & 0.000 & $2.013-7.206$ & 1.103 & 0.811 & $0.494-2.463$ \\
\hline $\mathrm{BUN}(\geq 30 \mathrm{mg} / \mathrm{dL})$ & 11.314 & 0.000 & $\begin{array}{l}4.950- \\
25.860\end{array}$ & 3.760 & 0.016 & $1.279-11.051$ \\
\hline Creatinine (> $1.5 \mathrm{mg} / \mathrm{dL})$ & 4.429 & 0.000 & $2.336-8.395$ & 1.070 & 0.881 & $0.442-2.590$ \\
\hline Albumin $(\leq 3.0 \mathrm{~g} / \mathrm{dL})$ & 37.509 & 0.000 & $\begin{array}{l}5.134- \\
274.040\end{array}$ & 7.360 & 0.072 & $0.839-64.574$ \\
\hline
\end{tabular}

$\mathrm{OR}$, odds ratio; $\mathrm{Cl}$, confidence interval; COPD, chronic obstructive pulmonary disease; NSAIDs, nonsteroidal anti-inflammatory drugs; SBP, systolic blood pressure; DBP, diastolic blood pressure; BUN, blood urea nitrogen; INR, international normalized ratio. 


\begin{tabular}{|c|c|c|c|c|c|c|}
\hline & \multicolumn{3}{|c|}{$\begin{array}{l}\text { Univariable logistic regression } \\
\text { analysis }\end{array}$} & \multicolumn{3}{|c|}{$\begin{array}{l}\text { Multivariable logistic regression } \\
\text { analysis }\end{array}$} \\
\hline & $\mathrm{OR}$ & $\begin{array}{l}\text { p- } \\
\text { value }\end{array}$ & $95 \% \mathrm{Cl}$ & OR & $\begin{array}{l}\text { p- } \\
\text { value }\end{array}$ & $95 \% \mathrm{Cl}$ \\
\hline INR (> 1.50) & 10.321 & 0.000 & $\begin{array}{l}5.310- \\
20.061\end{array}$ & 3.258 & 0.005 & $1.424-7.454$ \\
\hline \multicolumn{7}{|c|}{$\begin{array}{l}\text { OR, odds ratio; Cl, confidence interval; COPD, chronic obstructive pulmonary disease; NSAIDs, non- } \\
\text { steroidal anti-inflammatory drugs; SBP, systolic blood pressure; DBP, diastolic blood pressure; BUN, } \\
\text { blood urea nitrogen; INR, international normalized ratio. }\end{array}$} \\
\hline
\end{tabular}

Variables that were associated with all-cause mortality were collected separately, and the role of these variables was corrected and compared with the results of the multivariable logistic regression analysis to determine the extent of the role. Significant $(p<0.05)$ results were obtained with the following variables: heart rate $>100$ beats $/ \mathrm{min}(\mathrm{OR}, 13.134 ; \mathrm{p}=0.014 ; 95 \% \mathrm{Cl}, 1.677-102.880), \mathrm{BUN} \geq 30 \mathrm{mg} / \mathrm{dL}$ (OR, 3.760; $p=0.016 ; 95 \% \mathrm{Cl}, 1.279-11.051)$, and INR $>1.50(\mathrm{OR}, 3.258 ; \mathrm{p}=0.005 ; 95 \% \mathrm{Cl}, 1.424-7.454)$. Significant $(p<0.01)$ results were also obtained with the following variables: presence of cancer $(O R, 2.801 ; p=$ $0.071 ; 95 \% \mathrm{Cl}, 0.939-4.609)$ and albumin level $\leq 3.0 \mathrm{~g} / \mathrm{dL}(\mathrm{OR}, 7.360 ; p=0.072 ; 95 \% \mathrm{Cl}, 0.839-64.574)$ (Table 5).

(Table 5 was placed at the end of this manuscript )

\section{CNUH model for the prediction of mortality}

To determine the predictability of all-cause mortality from the variables, the AUROC was evaluated. Variables included were the presence of cancer, heart rate $>100$ beats $/ \mathrm{min}, \mathrm{BUN} \geq 30 \mathrm{mg} / \mathrm{dL}$, albumin level $\leq 3.0 \mathrm{~g} / \mathrm{dL}$, and INR $>1.50$.

Two models were compared. The first one was a $\mathrm{CNUH}-4$ model that incorporated the following variables: presence of cancer, heart rate $>100$ beats $/ \mathrm{min}, \mathrm{BUN} \geq 30 \mathrm{mg} / \mathrm{dL}$, and INR $>1.50$. The AUROC was drawn by assigning points from 0 to 4 . The second model (CNUH-5) was created by adding an albumin level $\leq$ $3.0 \mathrm{~g} / \mathrm{dL}$ to the $\mathrm{CNUH}-4$ model. The AUROC was drawn by assigning points from 0 to 5 .

The score distribution in the $\mathrm{CNUH}-4$ model was as follows: 0 points, 310 (33.5\%) patients; 1 point, 318 (34.3\%) patients; 2 points, 183 (19.8\%) patients; 3 points, 91 (9.8\%) patients; and 4 points, 24 (2.6\%) patients. The AUROC was 0.890 ( $<<0.001$; cutoff, $2.5 ; 95 \% \mathrm{Cl}, 0.0851-0.929)$ (Fig. 2). The score distribution in the CNUH-4 model was as follows: 0 points, $223(24.1 \%)$ patients; 1 point, $254(27.4 \%)$ patients; 2 points, 190 (20.5\%) patients; 3 points, 148 (16.0\%) patients; 4 points, 88 (9.5\%) patients; and 5 points, $23(2.5 \%$ ) patients. The AUROC was 0.901 ( $p<0.001$; cutoff, $3.5 ; 95 \% \mathrm{Cl}, 0.869-0.933$ ), which was higher than that of $\mathrm{CNUH}-4$ (Fig. 2).

The results of $\mathrm{CNUH}-4$ and $\mathrm{CNUH}-5$ were compared with those of $\mathrm{ABC}$ and AIMS65 using data from the Chungnam National University Hospital in 2020. The AUROC of $A B C$ was $0.881(p<0.001 ; 95 \% \mathrm{Cl}, 0.817$ - 0.945), the AUROC of AIMS65 was 0.861 ( $p<0.001 ; 95 \% \mathrm{Cl}, 0.771-0.951)$, the AUROC of CNHU-4 was 
$0.893(\mathrm{p}<0.001 ; 95 \% \mathrm{Cl}, 0.826-0.960)$, and the AUROC of CNUH-5 was $0.896(\mathrm{p}<0.001 ; 95 \% \mathrm{Cl}, 0.836-$ 0.956). When compared with data in 2020 , the AUROC of CNUH-5 was the highest (Fig. 3).

\section{Discussion}

Several studies have introduced indicators to predict the severity and mortality of UGIB [6] [7] [8]. Similar to UGIB, a scoring system that could predict the prognosis of LGIB using various predictors at the time of ER visit will be useful. Although the prognosis of LGIB is better than that of UGIB, it is very important to develop a scoring system to assess the mortality risk in advance. Therefore, we re-evaluated the risk factors using the existing scoring system, including only patients with LGIB and undergoing inpatient treatment, and developed a new scoring system for clinical use.

Prior to this study, other studies have evaluated the mortality and severity of LGIB. In these studies, heart rate $>100$ beats $/ \mathrm{min}$, systolic blood pressure $<115 \mathrm{mmHg}$, aspirin use, $\geq 2$ comorbidities [11], hematocrit $\leq 35.0 \%$, systolic blood pressure $<100 \mathrm{mmHg}$ or heart rate $>100 / \mathrm{min}$ [12], transfusion, re-bleeding, $20 \%$ reduction of hematocrit [13], prothrombin time $>1.2$-times the control, erratic mental status, unstable comorbidities [14], age $\geq 75$ years, creatinine level $>150 \mu \mathrm{mol} / \mathrm{L}$, and albumin level $\leq 30 \mathrm{~g} / \mathrm{L}$ [9] were found to be related with LGIB-induced severe morbidity and mortality.

Similar to previous studies, our univariable logistic regression analysis showed that specific vital signs, age, and laboratory test results were related to LGIB-induced mortality. However, in the multivariable logistic regression analysis, variables associated with all-cause mortality were the presence of cancer, heart rate $>100$ beats $/ \mathrm{min}, \mathrm{BUN} \geq 30 \mathrm{mg} / \mathrm{dL}$, albumin level $\leq 3.0 \mathrm{~g} / \mathrm{dL}$, and INR $>1.50$. When comparing the two models, $\mathrm{CNUH}-5$ had a higher AUROC value than $\mathrm{CNUH}-4$ (0.901 vs. 0.890$)$.

Two previous validation and derivation studies on LGIB severity have reported that the AUROC was 0.754 for the validation study and 0.761 for the derivation study $[11,15]$. In a study comparing the relationship between eight variables and 30-day mortality, the AUROC was 0.72 [16]. In a study that performed external validation with the existing NOBLADS score, the in-hospital mortality rate was $>5$ points (AUROC, 0.83) [17]. When compared with these studies, the AUROC of the CNUH model was found to be higher.

Few studies have evaluated the prognosis of LGIB. AIMS65, GBS, and Oakland scores have been found to be useful in assessing LGIB, and AIMS65 is known to be highly correlated with LGIB-related mortality [14] [18]. In this study, we compared AIMS65, which has the highest mortality prediction, with the recently developed ABC. Albumin level, INR, mental status, systolic blood pressure, and age are required to calculate the AIMS65 score, while age, BUN, albumin level, creatinine level, mental status, LC, malignancy, and ASA score are required to calculate the $\mathrm{ABC}$ score. However, the $\mathrm{CNUH}$ model does not include mental status, ASA score, and age; thus, a direct comparison was not possible. Therefore, we used the CNUH model as the comparator and validated the ABC and AIMS65 models.

The AUROCs of ABC, AIMS65, CNUH-4, and CNUH-5 with patient data in 2020 were $0.881,0.861,0.893$, and 0.896 , respectively. A slight difference was observed between the AUROCs of $\mathrm{CNUH}-4$ and $\mathrm{CNUH}-5$ 
when all enrolled patients were included. It is meaningful that the model presented in this study had a relatively higher AUROC than the two existing ones, although the patient's information or score calculation method was simpler with the CNUH model.

This study has certain limitations. In this retrospective study, all information was obtained from electronic medical records. This method does not provide adequate information on the change of conditions from the time of admission to death or discharge. LGIB often improves spontaneously and has a low mortality rate [19] [20] [21] [22]. Because of the low all-cause mortality rate, the OR values of some variables, such as heart rate, BUN, albumin, and INR, might be overcalculated. In addition, there might be a selection bias in targeting only patients hospitalized for LGIB. However, the scoring system was exclusively developed for patients who visited the hospital with hematochezia and in whom LGIB was clearly identified. Finally, this study was based on a single tertiary-care institution; our results need to be validated in other settings in a larger cohort.

In conclusion, we developed a model for predicting the risk of LGIB-related mortality. Five variables related to all-cause mortality were identified. The performance of our model was better than the existing ones. Further studies are required to validate our results in a larger cohort.

\section{Abbreviations}

ASA

American Society of Anesthesiologists

AUROC

area under the receiver operating characteristics curve

BUN

blood urea nitrogen

$\mathrm{Cl}$

confidence interval

COPD

chronic obstructive pulmonary disease

CT

computed tomography

ER

emergency room

GBS

Glasgow Blatchford Score

$\mathrm{HF}$

heart failure

INR

international normalized ratio

LC 
liver cirrhosis

LGIB

lower gastrointestinal bleeding

NSAIDs

non-steroidal anti-inflammatory drugs

OR

odds ratio

RF

renal failure

UGIB

upper gastrointestinal bleeding

\section{Declarations}

\section{Ethics approval and consent to participate}

This study was approved by the Institutional Review Board of Chungnam National University Hospital (IRB no. 2021-03-049). All procedures were performed in accordance with the ethical standards of the institutional and/or national research committee and with the 1964 Helsinki Declaration and its later amendments or comparable ethical standards.

Consent for publication: For this study, formal consent is not required.

\section{Availability of data and materials}

The datasets used and/or analysed during the current study are available from the corresponding author on reasonable request.

\section{Competing interests}

The authors declare that they have no conflict of interest.

\section{Funding}

The authors have no financial ties to disclose. The authors received no financial support for the research, authorship, and/or publication of this article.

\section{Authors' contributions}

HS provided ideas for conducting this study, IS performed statistical analysis and BS, SH, ES, JK, SHK organized the study data. All authors read and approved the final manuscript.

\section{Acknowledgment}


Not applicable.

\section{References}

1. ASGE Standards of Practice Committee; Pasha SF, Shergill A, Acosta RD, Chandrasekhara V, Chathadi KV, et al. The role of endoscopy in the patient with lower GI bleeding. Gastrointest Endosc. 2014;79:875-85.

2. Strate LL, Gralnek IM. ACG Clinical Guideline: Management of Patients With Acute Lower Gastrointestinal Bleeding. Am J Gastroenterol. 2016;111:459-74.

3. Gralnek IM, Neeman Z, Strate LL. Acute lower gastrointestinal bleeding. N Engl J Med. 2017;376:1054-63.

4. Lanas A, García-Rodríguez LA, Polo-Tomás M, Ponce M, Alonso-Abreu I, Perez-Aisa MA, et al. Time trends and impact of upper and lower gastrointestinal bleeding and perforation in clinical practice. Am J Gastroenterol. 2009;104:1633-41.

5. El-Tawil AM. Trends on gastrointestinal bleeding and mortality: where are we standing? World J Gastroenterol. 2012;18:1154-8.

6. Saltzman JR, Tabak YP, Hyett BH, Sun X, Travis AC, Johannes RS. A simple risk score accurately predicts in-hospital mortality, length of stay, and cost in acute upper Gl bleeding. Gastrointest Endosc. 2011;74:1215-24.

7. Marmo R, Koch M, Cipolletta L, Capurso L, Grossi E, Cestari R, et al. Predicting mortality in nonvariceal upper gastrointestinal bleeders: validation of the Italian PNED score and prospective comparison with the rockall score. Am J Gastroenterol. 2010;105:1284-91.

8. Blatchford O, Murray WR, Blatchford M. A risk score to predict need for treatment for uppergastrointestinal haemorrhage. Lancet. 2000;356:1318-21.

9. Farrell JJ, Friedman LS. Review article: the management of lower gastrointestinal bleeding. Aliment Pharmacol Ther. 2005;21:1281-98.

10. Laursen SB, Oakland K, Laine L, Bieber V, Marmo R, Redondo-Cerezo E, et al. ABC score: a new risk score that accurately predicts mortality in acute upper and lower gastrointestinal bleeding: an international multicentre study. Gut. 2021;70:707-16.

11. Strate LL, Orav EJ, Syngal S. Early predictors of severity in acute lower intestinal tract bleeding. Arch Intern Med. 2003;163:838-43.

12. Velayos FS, Williamson A, Sousa KH, Lung E, Bostrom A, Weber EJ, et al. Early predictors of severe lower gastrointestinal bleeding and adverse outcomes: a prospective study. Clin Gastroenterol Hepatol. 2004;2:485-90.

13. Newman J, Fitzgerald JE, Gupta S, von Roon AC, Sigurdsson HH, Allen-Mersh TG. Outcome predictors in acute surgical admissions for lower gastrointestinal bleeding. Colorectal Dis. 2012;14:1020-6. 
14. Kollef MH, O'Brien JD, Zuckerman GR, Shannon W. BLEED: a classification tool to predict outcomes in patients with acute upper and lower gastrointestinal hemorrhage. Crit Care Med. 1997;25:112532.

15. Strate LL, Saltzman JR, Ookubo R, Mutinga ML, Syngal S. Validation of a clinical prediction rule for severe acute lower intestinal bleeding. Am J Gastroenterol. 2005;100:1821-7.

16. Sengupta N, Tapper EB. Derivation and internal validation of a clinical prediction tool for 30-day mortality in lower gastrointestinal bleeding. Am J Med. 2017;130:601.e1-e8.

17. Aoki T, Yamada A, Nagata N, Niikura R, Hirata Y, Koike K. External validation of the NOBLADS score, a risk scoring system for severe acute lower gastrointestinal bleeding. PLoS One. 2018;13:e0196514.

18. Oakland K, Jairath V, Uberoi R, Guy R, Ayaru L, Mortensen N, et al. Derivation and validation of a novel risk score for safe discharge after acute lower gastrointestinal bleeding: a modelling study. Lancet Gastroenterol Hepatol. 2017;2:635-43.

19. Angtuaco TL, Reddy SK, Drapkin S, Harrell LE, Howden CW. The utility of urgent colonoscopy in the evaluation of acute lower gastrointestinal tract bleeding: a 2-year experience from a single center. Am J Gastroenterol. 2001;96:1782-5.

20. Browder W, Cerise EJ, Litwin MS. Impact of emergency angiography in massive lower gastrointestinal bleeding. Ann Surg. 1986;204:530-6.

21. Chaudhry V, Hyser MJ, Gracias VH, Gau FC. Colonoscopy: the initial test for acute lower gastrointestinal bleeding. Am Surg. 1998;64:723-8.

22. Longstreth GF. Epidemiology and outcome of patients hospitalized with acute lower gastrointestinal hemorrhage: a population-based study. Am J Gastroenterol. 1997;92:419-24.

\section{Figures}




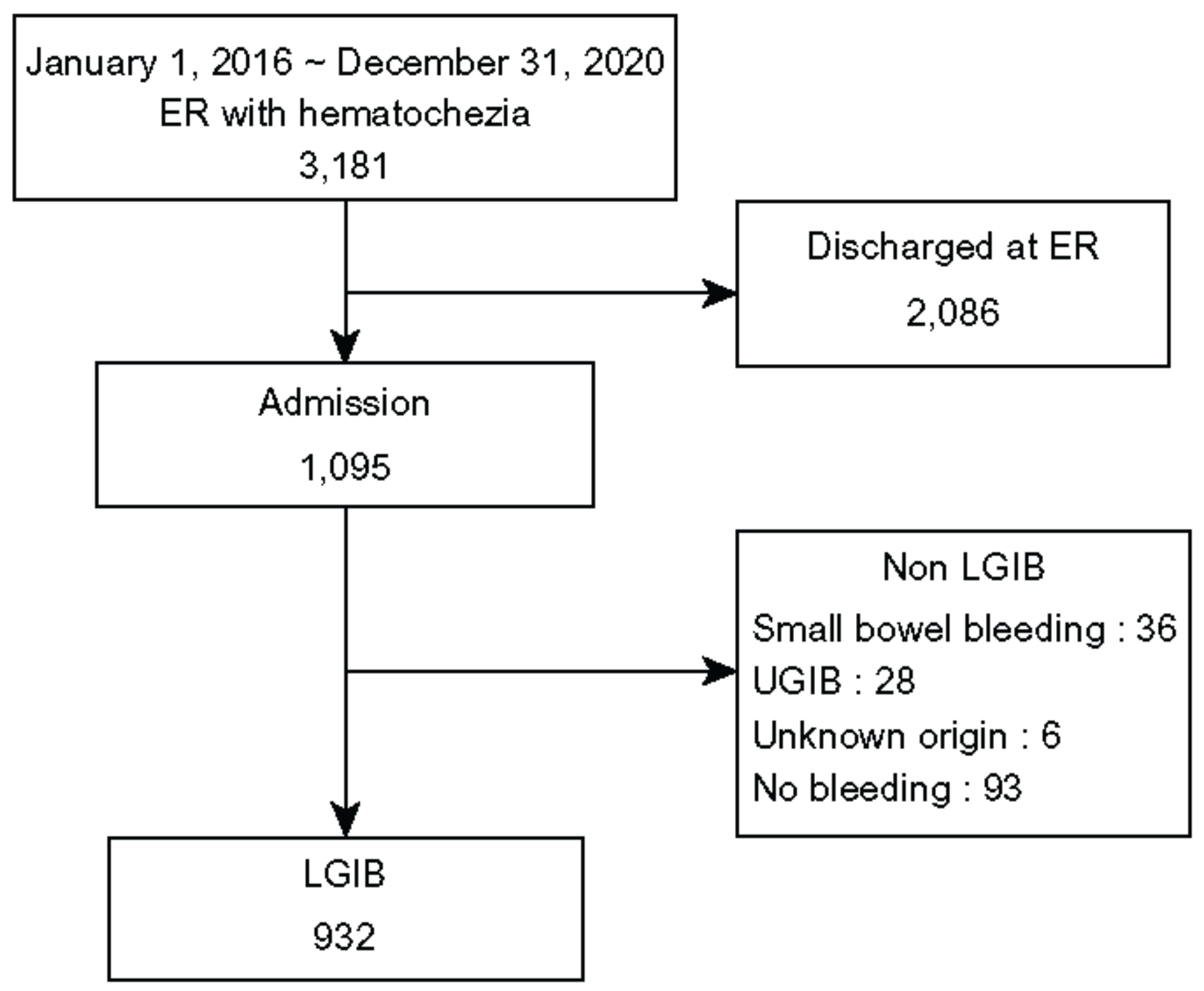

Figure 1

Study flow chart. 

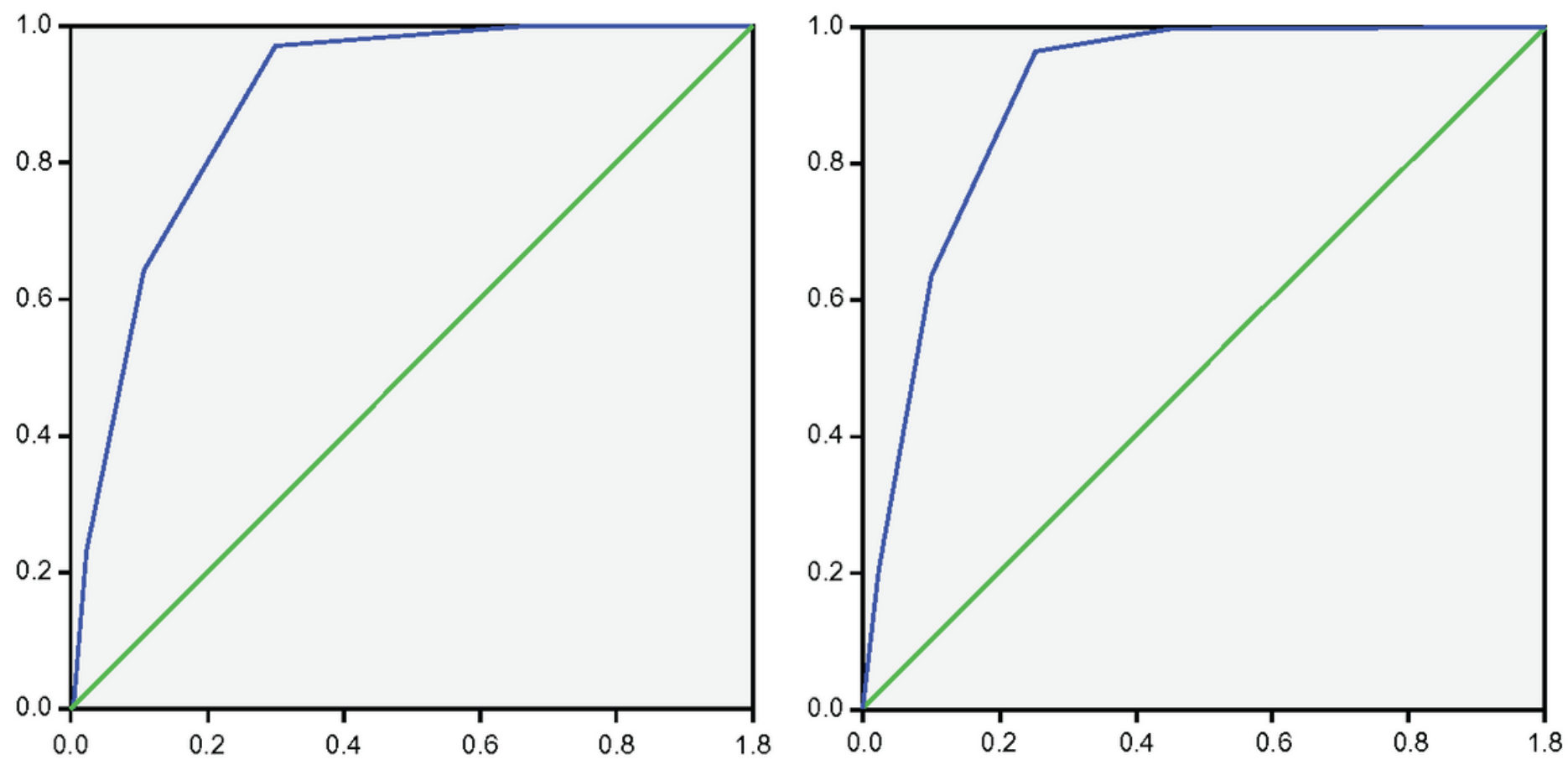

Figure 2

Comparison of the area under the receiver operating characteristics curve (AUROC) between CNUH- 4 and CNUH-5. The AUROC of CNUH-4 (left) was 0.890 ( $p<0.001$; cutoff, $2.5 ; 95 \% \mathrm{Cl}, 0.0851-0.929$ ). The AUROC of CNUH-5 (right) was 0.901 ( $p=0.000$; cutoff, $3.5 ; 95 \% \mathrm{Cl}, 0.869-0.933)$. $x=1$-sensitivity, $y=$ sensitivity 

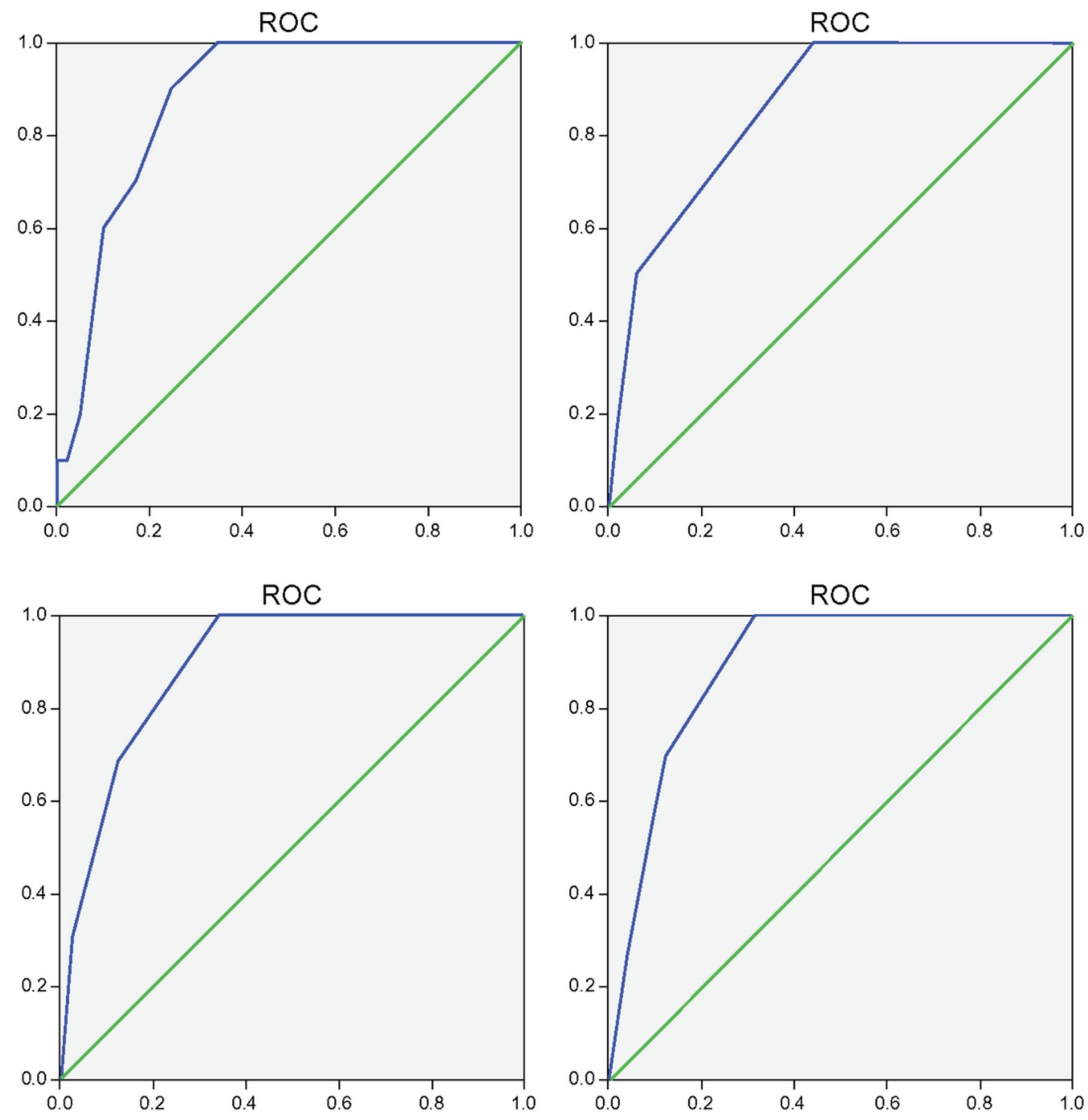

\section{Figure 3}

Comparison of various models using patient data in 2020. The area under the receiver operating characteristics curve (AUROC) of ABC (left upper) was 0.881 ( $\mathrm{p}<0.001 ; 95 \% \mathrm{Cl}, 0.817-0.945)$, the AUROC of AIMS65 (right upper) was 0.861 ( $p<0.001 ; 95 \% \mathrm{Cl}, 0.771-0.951$ ), the AUROC of CNHU-4 (left lower) was $0.893(p<0.001 ; 95 \% \mathrm{Cl}, 0.826-0.960)$, and the AUC of $\mathrm{CNUH}-5$ (right lower) was 0.896 ( $p<0.001 ; 95 \%$ $\mathrm{Cl}, 0.836-0.956)$. $x=1$-sensitivity, $y=$ sensitivity 